\title{
Consciência de Estudantes Prounistas sobre sua Inserção no Ensino Superior
}

\author{
Flávia de Mendonça Ribeiro \\ Pontifícia Universidade Católica de Campinas, \\ Campinas, SP, Brasil.
}

\author{
Raquel Souza Lobo Guzzo \\ Pontifícia Universidade Católica de Campinas, \\ Campinas, SP, Brasil.
}

Resumo: Este artigo visa analisar a consciência de bolsistas do Programa Universidade para Todos (ProUni), partindo da compreensão apresentada por eles sobre sua inserção e vivência na graduação. Primeiramente, faz-se uma descrição histórica do Ensino Superior brasileiro, focando na política educacional do ProUni, em seguida uma leitura da Psicologia Crítica e do papel do psicólogo no Ensino Superior, finalizando na descrição do Processo de Tomada de Consciência. As técnicas para busca de dados foram diários de campo de uma das autoras das reuniões presenciais e etnografia virtual de um grupo virtual de prounistas. Foram sistematizadas cinco categorias de análise a partir da etnografia virtual e, além dessas, mais uma (totalizando seis) categoria de análise pelos quatro diários de campo. São elas: Assistência e Permanência Estudantil, Comprovação de renda, Organização do grupo, Preconceito, Visão do ProUni e Solidariedade entre prounistas. A análise dos dados relacionou os objetivos e as informações obtidas. Foi encontrada uma maior quantidade de mulheres participantes dos grupos presencial e virtual. No grupo virtual apenas a primeira forma de consciência - alienação - foi encontrada na maioria dos estudantes. Nas reuniões presenciais, por estarem vivenciando a organização conjunta, foi possível identificar todas as formas desse processo. Concluiu-se que foi possível identificar diferenças no processo de tomada de consciência dos estudantes prounistas partindo dos espaços de auto-organização. Necessita-se de maiores estudos sobre como o preconceito vivenciado pelos prounistas influencia em seu processo de tomada de consciência.

Palavras-chave: Psicologia Crítica, Ensino Superior, Consciência, Reforma Universitária, ProUni.

\section{Awareness of ProUni Students about their Insertion in Higher Education}

\begin{abstract}
This article aims to analyze the awareness of scholarship students of the University for All Program (ProUnistas) from the conception they have about their experiences and insertion in undergraduate courses. First, a historical description of the Brazilian higher education, focusing on educational policy ProUni was made; then a reading of Critical Psychology and the role of psychologists in Higher Education was performed; finally, a description of the Consciousness Process was conducted. The techniques used for search data were one of the authors' field diaries of the face-to-face encounters and a virtual ethnography meetings of a virtual group of ProUnistas. Five categories of analysis were systematized based on the virtual ethnography and, in addition, one (totaling six) additional category of analysis was included out ot the four field diaries. The identified categories were: Students Care and Permanence, Proof of income, Group organization, Prejudice, Vision of ProUni, and Solidarity between ProUnistas. The analysis of data established a relation between the objectives the information obtained. A greater number of women were found to be present in the virtual and face-to-face groups. In the virtual group only the first form of consciousness - alienation - was found in most students. In the in-person meetings, it was possible to identify all forms of this process, because students experience joint organization. It was concluded that it was possible to identify differences in the awareness of ProUnistas starting from spaces for self-organization processes. Further studies on how prejudice experienced by ProUnistas influences their process of awareness are needed.
\end{abstract}

Keywords: Critical Psychology, Higher Education, Consciousness, University Reform, ProUni. 


\title{
La Concientización de los Estudiantes Prounistas en su Inserción en la Educación Superior
}

\begin{abstract}
Resumen: Este artículo propone analizar la concientización de los becarios del Programa Universidad para Todos, empezando por su comprensión acerca de sus experiencias e inserción en el nivel de pregrado. Primero se hace una descripción histórica de la educación superior de Brasil, centrada en la política educativa ProUni; luego es hecha una lectura a partir de la Psicología Crítica y el papel de los psicólogos en la educación superior; finalmente, es hecha una descripción del proceso de concientización. Las técnicas para recolección de datos fueron diarios de campo de la autora y etnografía virtual de un grupo virtual de ProUnistas. Fueran sistematizadas cinco categorías de análisis a partir de la etnografía virtual y, además de estos, una más (un total de seis) a partir de los cuatro diarios de campo. Las categorías identificadas son: Cuidado y permanencia del estudiante, Comprobante de ingresos, Organización del grupo, Prejuicio, La visión del ProUni y La solidaridad entre ProUnistas. Los datos fueron analizados a partir de los objetivos y de los datos obtenidos. En el grupo virtual solo la primera forma de concientización - la alienación se encuentra en la mayoría de los estudiantes. En las reuniones presenciales, por involucrar una organización conjunta, fue posible identificar todas las formas de este proceso. Se concluyó que es posible identificar diferencias en la concientización de los estudiantes ProUnistas dejando espacios para el proceso de auto-organización. Se necesitan más estudios acerca de cómo el prejuicio experimentado por los ProUnistas influye en el proceso de concientización.
\end{abstract}

Palabras clave: Psicología Crítica, Educación Superior, Consciencia, Reforma Universitaria, ProUni.

Atualmente, muitos estudantes de escolas públicas ingressam no Ensino Superior a partir do Programa Universidade para Todos (ProUni), adquirindo bolsas de estudos, integrais ou parciais, em instituições privadas (ProUni, 2008). Enquanto forma de acesso ao Ensino Superior, o programa cumpre seu papel, mas falha com a falta de políticas de permanência estudantil para os bolsistas. Ou seja, ausência de auxílios como alimentação com preço acessível, transporte universitário, bolsas trabalho, biblioteca com os livros e materiais didáticos necessários, são exemplos da falta de políticas de permanência para os estudantes prounistas. Isso faz com que eles enfrentem muitas dificuldades para se manterem nos cursos de graduação pelos altos custos, principalmente nas instituições privadas (Vasconcelos, 2010). É nesse contexto que esse trabalho se justifica, pois, apresenta dados de como é visão e a organização desses estudantes, e como poderá ser o papel da Psicologia em seu auxílio psicossocial frente às vivências universitárias.

Para atingir o objetivo da pesquisa, algumas questões foram apresentadas e respondidas: Quem são os prounistas?; Eles sabem o que é o ProUni e como foi implementado?; Na visão dos estudantes, a educação é direito ou favor?; Como é a vivência do prounista dentro da Instituição de Ensino Superior (IES)?; É necessário mudar essa realidade?; Como mudar essa realidade?

O fundamento teórico será apresentado em dois eixos: o primeiro contextualizando o processo de criação do ProUni nas IES Privadas do Brasil e o segundo eixo indicando qual o papel do psicólogo escolar no ensino superior e como é o processo de tomada de consciência no contexto universitário.

\section{As instituições de ensino superior no Brasil e a implementação do ProUni: que tipo de universidade queremos?}

Durante quase 50 anos, a Organização das Nações Unidas para a Educação, a Ciência e a Cultura (Unesco) e o Banco Mundial, com interferência dos EUA, formularam livros, textos e conferências mundiais (como a de Bretton Woods) que chegavam à mesma conclusão neoliberal: para os países da América Latina se desenvolverem, ao ponto de se tornarem países de primeiro mundo, deveriam, imediatamente, descentralizar os serviços básicos do Estado, como assistência social, saúde e educação, por exemplo, e privatizá-los (Lima, 2007), concedendo às empresas privadas a possibili- 
dade de investir capital privado no setor público e concedendo ao serviço público possibilidade de investir capital público no setor privado, para suprir as demandas sociais da população latino-americana, a Parceria Público-Privada (PPP) (Leher, 2004).

Seguindo essa lógica neoliberal, em 1995, no governo de Fernando Henrique Cardoso (FHC), reorganizou um anteprojeto da Reforma Universitária para que houvesse PPP nas IES, como ter pesquisadores de universidades públicas como consultores de empresas privadas, até a cobrança de uma mensalidade em universidades públicas, ou o regime de bolsas de estudo para estudantes de baixa renda em instituições privadas (futuro ProUni) foram algumas das muitas propostas que explicitaram o intuito do governo em privatizar a educação (Lima, 2007). Por fim, em 2004, o começo da Reforma Universitária foi implementado durante o governo Lula, sendo que o ProUni, assim como os seus outros quatro eixos estão, direta ou indiretamente, ligados à PPP (Leher, 2004).

O ProUni foi implementado em 2005, no governo Lula, e concedeu bolsas de estudos, integrais ou parciais, a estudantes de escolas públicas em instituições privadas, em troca de isenção de impostos (ProUni, 2008), como Contribuição para o Financiamento da Seguridade Social - Cofins- e Imposto de Renda de Pessoa Jurídica - IRPJ (Silva, Koike, Manezenco, \& Lacks, 2004). Além da concessão de bolsas aos estudantes que cursaram Educação Básica na rede pública, o ProUni também concede bolsas à deficientes físicos, estudantes de escolas particulares que comprovem a isenção total do pagamento da mensalidade e, ainda, para professores da rede básica de ensino que não possuem o diploma de licenciatura. Nesse último caso, a comprovação de renda per capita não é considerada, entretanto nos outros casos, é necessária a comprovação de renda per capita de até três salários mínimos (ProUni, 2005).

Desde a criação do ProUni até 2013, foram isentos mais de $\mathrm{R} \$ 4$ bilhões em impostos (Foreque, 2013), dinheiro que, se fosse investido em IES públicas, poderia auxiliar na inclusão e permanência desses estudantes nessas instituições públicas (Almeida, 2009). O número de evasão de prounistas, desde sua criação até 2011, é de 11,5\%, mas o Ministério da Educação (MEC) afirma que alguns desses alunos permanecem no Ensino Superior começando a pagar por sua graduação (Weber, 2011). Porém, há os que saem por não ter assistência estudantil e não conseguem permanecer na universidade. Não há iniciativa das IES privadas em promover assistência estudantil para permanência de estudantes bolsistas. Isso se comprova com as informações divulgadas no Relatório de Auditoria Operacional: ProUni e FIES, do Tribunal de Contas da União (TCU) publicado em 2009, em que a IES recebe a isenção de imposto pelo acesso [grifo nosso] do estudante à graduação, e, se por algum motivo, ele evadir-se da IES, a isenção continuaria a ser mantida (Jorge, 2009).

Somente para estudantes que estão matriculados em cursos integrais e que tem mais de $6 \mathrm{~h}$ /aulas/diárias o governo federal fornece uma bolsa mensal com valor igual à Iniciação Científica (hoje de R \$ 400) para auxiliar na permanência do estudante na IES (ProUni, 2008). De 2005 até 2013, 1.920.312 bolsas integrais e parciais do ProUni foram ofertadas pelas IES particulares (ProUni, 2013), porém não há disponível o número de estudantes prounistas que recebem bolsa permanência. Segundo os estudos realizados por Costa (2008), Pereira Filho (2011) e Rocha (2011), o perfil dos bolsistas do ProUni pode ser caracterizado como a maioria de estudantes mulheres, de 18 a 24 anos, de baixa renda e com graduação em cursos das Ciências Humanas. Para conseguir a bolsa integral do ProUni é necessário que o estudante tenha no máximo um salário mínimo e meio por renda familiar, e para bolsa de $50 \%$ é necessário que o estudante tenha renda familiar de no máximo três salários mínimos. Como a maioria das IES colocam aos estudantes as bolsas parciais, ou seja, durante a graduação, o prounista também paga para a IES metade da mensalidade, muitos desses estudantes precisam trabalhar para sustentar sua permanência na IES ou mesmo sustentar suas famílias. Esse fato é comprovado por Costa (2008), quando afirma que $73,8 \%$ dos prounistas trabalham para sustentar sua família ou a si mesmo.

\section{O Psicólogo no ensino superior e o processo de tomada de consciência nesse contexto}

Na sociedade capitalista, grande parte das profissões de nível superior são voltadas à manutenção do sistema econômico, enquanto parte majoritária da sociedade, encontra-se excluída da formação profissional (Guzzo, 2007; Marvakis, 2011). A Psicologia é uma dessas profissões, cuja perspectiva dominante atribui ao indivíduo a responsabilidade por sua situação atual. Muitos psicólogos são formados para rea- 
firmar e construir esse sistema em que vivemos, não questionando o que lhes é ensinado, aceitando um currículo, muitas vezes, incompleto, conservador e superficial e que, no final do curso, reproduzem o que foi ensinado sem avaliar ou criticar seu conteúdo, instrumentos de trabalho e consequências das ações profissionais (Guzzo, 2007).

A Psicologia Crítica, de acordo com Parker (2009), estuda as maneiras em que as vertentes da Psicologia são construídas, cultural e historicamente, e como as vertentes alternativas dessa ciência podem legitimar ou resistir às presunções ideológicas dos modelos dominantes. Ainda, seria aquela que explora a maneira em que a Psicologia cotidiana estrutura o trabalho acadêmico, o trabalho do psicólogo, e como as atividades diárias podem prover a base para resistir às práticas disciplinares contemporâneas e conservadoras.

O psicólogo que adota a perspectiva crítica em sua atuação nas IES, pode atuar com funcionários, professores e estudantes, além de desenvolver discussões sobre o currículo e projeto político pedagógico do curso de Psicologia, construindo uma formação problematizadora do estudante (Guzzo, 2007). Focando na atuação com os estudantes, o fortalecimento do sujeito é base para seu trabalho, auxiliando o exercício político e crítico de sua participação na sociedade, visando a mudança da realidade em que vivem (Martín-Baró, 1996), fazendo uma orientação coletiva, encaminhamentos internos e externos, atendimento às famílias e comunidade, entre outras ações (Carvalho, \& Marinho-Araújo, 2009; Bisinoto \& Marinho-Araújo, 2011; Bisinoto, Marinho, \& Almeida, 2011).

O Ensino Superior é um campo amplo para o psicólogo escolar, pois, em algumas IES não há nenhum programa que dê apoio aos estudantes visando suprimir vários problemas cotidianos (Serpa, \&Santos, 2001), inclusive o de permanência na instituição, outra possibilidade de atuação do psicólogo. Segundo Martín-Baró (1996), quando formos definir nosso papel e identidade enquanto psicólogos, independente do lugar de atuação, devemos levar em consideração a situação histórica de nossa sociedade e suas necessidades a partir das demandas reais da população a ser beneficiada por nossos serviços. Devemos, então, desenvolver um papel mediador no processo de superação da alienação em sua identidade pessoal e social, na medida em que problematiza as condições opressivas em seu contexto.

A superação da alienação faz parte do Processo de Tomada de Consciência (PTC), denominado por
Iasi (2011) como um processo que envolve três características distintas: alienação, consciência em si e consciência para si. Porém, no desenvolvimento desse processo, é necessário levar em conta dimensões psicossociais presentes no cotidiano e que afetam a trajetória de quem ingressa no Ensino Superior.

A consciência humana, segundo Duarte (2004), é a relação entre o sentido da ação (dado por aquilo que liga o objeto da ação ao motivo da ação) e o significado da ação (aquilo que o sujeito faz), mediada indiretamente pelo todo. Iasi complementa afirmando que a consciência é "o processo de representação mental (subjetiva) de uma realidade concreta e externa (objetiva), formada nesse momento, através do seu vínculo de inserção imediata (percepção), (...) [ou seja,] a realidade externa que se interioriza" (Iasi, 2011, p. 14). Então, entende-se que a tomada de consciência pode possibilitar a mudança desejada.

Por outro lado, a alienação, segundo Iasi (2011), a primeira forma do PTC, é dissociação entre o que o indivíduo faz daquilo que motiva aquela ação. E esse distanciamento entre seu trabalho e o que é fruto dele no mundo torna as pessoas distantes de uma clareza do que é possível mudar. A perda da capacidade de acreditar que mudanças são possíveis pela ação direta das pessoas no mundo é denominada de fatalismo, por Freire (1984), como aquilo que nos leva ao cruzamento dos braços e à impossibilidade de fazer algo diante dos fatos e o poder provindo deles. Os pensamentos fatalistas só dificultam o processo de tomada de consciência.

Como apontaram Lacerda Junior e Guzzo (2011), referindo-se a Martín-Baró, é necessário que haja um processo em que, as pessoas elaboram o conhecimento sobre a realidade, tendo como base as reais necessidades e desmascarando a ideologia dominante que naturaliza a história e cristaliza as possibilidades de mudança. Esse processo, de acordo com Martín-Baró (1985), significa resgatar a experiência original dos grupos e pessoas e devolvê-las como dado objetivo. Isso permitirá formalizar a consciência, a partir da sua própria realidade, além de verificar a validez do conhecimento adquirido. Para esse autor ainda, trata-se de um processo que estimula a participação popular, a partir do momento em que as pessoas passam a lutar por seus direitos mesmo que não sejam realmente aplicados.

Iasi (2011) afirma que a segunda forma do PTC, consciência em si ou das reivindicações, ocorre quando o indivíduo reconhece o outro como companheiro de luta contra a injustiça vivida e essa passa a ser a chave 
para a luta coletiva, é a forma mais básica de consciência nas lutas sociais. Já a última forma do PTC, ainda para o mesmo autor, é a consciência para si, consciência de classe, ou ainda consciência revolucionária. Estas seriam a forma mais completa e emancipadora de consciência, superando a consciência em si, pois leva o sujeito à prática da mudança social, à práxis prática com sentido social, com intencionalidade.

Todos os autores citados (Duarte, 2004; Freire, 1979; 1984; Guzzo, 2007; 2010; Iasi, 2011; Lacerda Junior, \& Guzzo, 2011; Martín-Baró, 1985; 1996) acreditam e defendem que a única saída para a libertação e emancipação de homens e mulheres é a ação coletiva e popular, como resultado do processo de tomada de consciência. Com isso, Guzzo (2010) propõe como ação do psicólogo dentro da universidade a construção de um currículo crítico a partir de quatro pontos essenciais: 1. Propor a eliminação do analfabetismo político e desenvolver o compromisso social, vencendo assim a alienação; 2 . Exercitar na prática a discussão das contradições, vencendo o saber instituído; 3. Aprender a tomar decisões e avaliar as consequências, vencendo assim a insegurança profissional; 4. E por último, "exercer, avaliar e construir as políticas públicas e sociais com a Psicologia, respondendo à realidade e superando as amarras do fatalismo" (Guzzo, 2010, p.177).

\section{Objetivo}

O presente artigo tem como objetivo analisar a consciência dos estudantes bolsistas do ProUni, a partir da concepção que eles têm de sua inserção no Ensino Superior, frente à conjuntura em que vivem.

\section{Método}

Trata-se de uma pesquisa qualitativa que vê a ação social como experiência para produção do conhecimento (Parker, 2005). A pesquisa ainda teve como inspiração o Materialismo Histórico Dialético (MHD), que, segundo Paulo Netto (2011) é um método complexo que se pauta, principalmente em três eixos interligados (totalidade, mediação e contradição). Esse método é uma forma de compreender a realidade em que vivemos, a partir das condições materiais de vida, as ações, que sujeitos reais praticam, o que realmente precisam construir, para assim, conseguirem agir e mudar a realidade em que vivem. Esta análise funda-se na compreensão dialética em que fenômenos são processos, considerados historicamente, a partir do qual se busca a transformação do fenômeno e da realidade. A leitura da realidade, a partir do MHD, evidencia a totalidade, a qual não é um conjunto de partes, mas sim um todo complexo composto por totalidades menos complexas e que cada uma tem uma importância para a determinação dos fatos. A compreensão dialética (caráter processual e em constante transformação da realidade) é importante para mediar essa relação entre as totalidades e a contradição que as torna dinâmicas e mutáveis.

\section{Fontes e técnicas de informação}

Para a realização da pesquisa foram utilizadas duas técnicas para busca de informações: diários de campo e etnografia virtual.

- A Etnografia Virtual, também conhecida como netnografia ou etnografia on-line (Amaral, 2009; Hine, 2000; Mercado, 2012; Montardo, \& Passerino, 2006; Pieniz, 2009) é uma técnica relativamente nova que surgiu por volta de 2000 , e tem a internet como fonte de informação para pesquisas já que há a possiblidade de um estudo detalhado das relações criadas e vividas em espaços virtuais, a partir da escrita ou imagem (Mercado, 2012). Com isso, as informações do grupo virtual estão on-line, num grupo aberto, ou seja, todos podem acessar essas informações. Então, sobre a questão ética, os autores Jeffrey, Bradshaw, Twining e Walsh (2010) detalham como seria a defesa pela identidade anônima dos participantes, o que foi realizado nessa pesquisa. Mesmo não se tratando de uma pesquisa presencial, face a face, a ética em pesquisas de etnografia virtual não pode ser desconsiderada, afinal, ainda assim estamos lidando com seres humanos, mesmo que de forma diferenciada. É necessário fazer uma distinção entre as informações difundidas publicamente e as acessíveis ao público, quando nos referimos ao uso de dados on-line. Nesse último tipo, não se faz necessário pedir consentimento de participação, pois nos grupos sociais on-line muitas vezes não são utilizados dados de identificação e sim pseudônimos, garantindo uma autonomia visual e o anonimato. Na etnografia virtual a "simples observação" é uma das práticas mais utilizadas, a fim de deixar o lugar a ser estudado mais espontâneo possível. No entanto, é necessário anunciar nossa presença no grupo para que as 
pessoas possam escolher entre continuar se manifestando no grupo ou ausentar-se do espaço virtual. Uma etnografia de, na e através da internet pode ser concebida como uma abordagem adaptativa e parcial que se baseia em conexões virtuais ao invés de conexões locais na definição de seu objeto (Jeffrey et al., 2010).

- Os diários de campo, segundo Montero (2006), são relatos feitos por uma das pesquisadoras contendo suas impressões, observações, e percepções do objeto a ser estudado relacionando-o com a teoria, se tornando assim uma fonte de construção de dados para a pesquisa.

\section{Cenário da pesquisa e participantes}

Em 2011, cerca de dez estudantes bolsistas do ProUni de uma IES privada do estado de São Paulo se conheceram no movimento estudantil dessa IES, no campus de áreas da saúde/humanas, defendendo uma reivindicação unitária por restaurante universitário a baixo custo (chamado "A gente não quer só comida"). Os estudantes perceberam que alguns dos prejudicados pelo alto preço da alimentação vendida no refeitório eram os estudantes bolsistas do ProUni (que se autodenominavam prounistas). Resolveram, então, fazer um grupo de discussão aberto em uma rede social para conversarem sobre suas vivências e as dificuldades encontradas para permanecerem dentro da universidade, inclusive como poderiam se organizar dentro do movimento "A gente não quer só comida". Cada pessoa inserida no grupo poderia adicionar outras pessoas, sendo prounista ou não, que se interessassem em ajudar na construção do movimento. Foi assim que uma das pesquisadoras foi inserida no grupo que contém 113 estudantes, mas somente 60 participavam ativamente. Nesse espaço virtual, alguns participantes resolveram marcar uma reunião presencial para discutirem como seriam os próximos passos, pautas do movimento, nome do coletivo, além de manterem as discussões pelo grupo virtual.

As e os estudantes resolveram chamar o grupo em seu formato virtual e presencial de Fórum de Prounistas, por suscitar o debate e construção conjunta das demandas oriundas do grupo, tais como um restaurante universitário, micro-ondas, geladeira, bolsa permanência para cursos integrais, bolsa trabalho e o fim da comprovação de renda anual pelos prounistas, entre outras formas de ação não só relaciona- das ao movimento dos prounistas. O movimento foi aos poucos obtendo resultado positivo em suas reivindicações, além de construírem um material para recém-ingressos no programa. Realizavam reuniões quinzenais, com média de 10 estudantes presentes, e rotatividade de 18 estudantes no total.

\section{Processo de busca das informações}

Como já explicitado, foram utilizadas duas técnicas de busca de informações. Primeiramente, utilizando a etnografia virtual, as pesquisadoras selecionaram todo o conteúdo on-line do "grupo virtual", desde sua criação até o período que começou a análise da pesquisa, totalizando oito meses, e o copiou em um arquivo do software Microsoft Word, para melhor manuseá-lo. Em seguida, listou todos os estudantes que se manifestaram no grupo virtual e/ou no grupo presencial em Participante 1 (P1), P2, P3, ..., P67, sendo que a participação no grupo virtual acontecia curtindo postagens, respondendo questões, tirando dúvidas, colocando suas opiniões, tentando marcar reuniões, questionando normas das IES e do ProUni, entre outros. Essas informações foram colhidas a partir dos perfis da rede social, e de comentários dentro do próprio grupo virtual que relacionavam sua vivência ao curso que faziam.

Por fim, foram feitas sucessivas leituras desse material, e, dessa análise, foram organizados cinco temas que representaram as unidades de sentido presentes na discussão dos estudantes: Assistência e Permanência Estudantil, Comprovação de renda, Organização do grupo, Preconceito e Visão do ProUni.

A partir da segunda técnica, foram feitos quatro diários de campo (DC1, DC2, DC3 e DC4) decorrentes da participação em quatro reuniões do Fórum de Prounistas, aqui denominado "grupo presencial". Os participantes citados nos diários foram identificados com a mesma sistematização do grupo virtual, para melhor compreensão do processo de atuação no movimento. Nos relatos foram colocadas as impressões de uma das pesquisadoras sobre a discussão, de acordo com a teoria estudada, além de descrição dos estudantes que participaram das reuniões, o local da reunião etc. Depois de finalizados os diários de campo, as anotações foram relidas com o intuito de selecionar os temas mais discutidos nas reuniões. Além dos cinco temas de unidades de sentido presentes no grupo virtual, o tema Solidariedade entre prounistas também 
apareceu nas discussões presenciais, totalizando em seis temas de unidades de sentido.

\section{Resultados e Discussões}

Com a intensão de responder as questões levantadas anteriormente, a apresentação dos resultados dar-se-á em dois momentos: um, relativo à caracterização dos participantes do grupo virtual e do grupo presencial, com breve análise sobre os participantes e outro momento com uma tabela descritiva relacionando as seis categorias encontradas e os dois tipos de fonte de informação, a fim de responder às questões acima mencionadas.

\section{Caracterização geral dos participantes: grupo virtual e grupo presencial}

Como os dois grupos virtual e presencial se relacionam, os dados se complementam na caracterização dos participantes, então, no total participaram ativamente da pesquisa 67 estudantes (P1 - P67), sendo que 11 participaram tanto do grupo virtual quanto do presencial, 49 participaram somente do virtual e sete apenas participaram do grupo presencial - totalizando 18 participantes do grupo presencial. Não se pode identificar a faixa etária dos estudantes, pois os perfis na rede social não disponibilizavam essa informação publicamente e eles não comentaram sobre o tema em nenhum dos grupos. Entretanto, o curso dos participantes e o gênero foi possível caracterizar. Portanto, os estudantes dos seguintes cursos participaram da pesquisa: Direito (3\%), Farmácia (3\%), Fisioterapia (7,5\%), Medicina (45\%), Nutrição (1,5\%), Odontologia (1,5\%), Psicologia (34\%) e indefinidos - pessoas que participaram, mas não havia como identificar seu curso (4,5\%). Já em relação a gênero, 42 mulheres (63\%) e 25 homens (37\%).

Costa (2008), Pereira Filho (2011) e Rocha (2011) afirmam que há mais mulheres que homens bolsistas do ProUni, o que também foi percebido nesse estudo, com quase $63 \%$ de participantes mulheres. Nesse caso, os autores também afirmam, como é verificado nas reuniões do grupo presencial e do grupo virtual, que todos os estudantes são baixa renda, a partir do que relataram nas reuniões. Também no grupo presencial foi indicado terem sido primeiros da família a entrarem em uma IES. Houve casos de irmãos que entraram em alguma universidade, mas evadiram por causa do trabalho. Outros estudantes, não contabilizados enquanto participantes do grupo presencial, chegaram a passar algumas vezes antes da reunião começar, para explicar que não iriam participar, pois tinham que ir ao trabalho e que os horários das reuniões eram incompatíveis com os do horário de trabalho, apesar de entenderam a importância da auto-organização.

Em relação à afirmação de Pereira Filho (2011) que o ProUni garante a entrada de negros e pardos na IES, não se pôde comprovar tal afirmação, já que poucos negros e pardos participaram da pesquisa. Mas, assim como afirmam Almeida (2006) e Carvalho (2006), embora os estudantes tenham o direito à educação pública, gratuita e de qualidade, muitas vezes, não conseguem, mesmo que ingressem no ensino superior pelo ProUni, finalizar sua formação com qualidade, como explicitado pelos estudantes nos grupos virtual e presencial.

\section{Análise por categorias encontradas}

Como já explicitado anteriormente, após contínuas leituras do material recolhido foi realizada uma sistematização de temas que mais apareceram nas discussões do grupo virtual e dos diários de campo. Nessa análise foram organizados seis temas que representaram as unidades de sentido presentes na discussão dos estudantes. São elas: Assistência \& Permanência Estudantil, Comprovação de renda, Organização do grupo, Preconceito, Visão do ProUni e Solidariedade entre prounistas. Sendo que a última apareceu apenas nos diários de campo da pesquisa. Podemos identificar que algumas categorias estão relacionadas e aparecem tanto nos diários de campo quanto nos registros da etnografia virtual, sendo que na mesma fonte de informação apareceram mais de uma categoria.

A categoria Visão do ProUni está presente juntamente com a categoria Assistência \& Permanência Estudantil, na reunião descrita no DC04 e no grupo virtual. Podemos apontar na seguinte passagem posicionamentos de prounistas que remetem à mesma visão apresentada por Pereira Filho (2011), quando este afirma que alguns estudantes elogiam o ProUni e outros apontam o mesmo como um programa social paliativo, pois não promove assistência estudantil.

P42 disse (...) explicariam o que é o Programa apenas [em escolas públicas]. P67 disse, então que não concordava em fazer aquilo, pois se elas fossem falar sobre o ProUni, iriam de uma 
forma ou de outra ou falar bem, ou falar mal, pois mesmo quando você não se posiciona contra ou a favor, ainda assim tem um posicionamento. $\mathrm{P} 12$ disse então, que seria interessante que eles fossem às escolas falar sobre as universidades públicas e assim fazer um contraponto em relação ao ProUni, dizer que ele existe, mas que não é suficiente (DC04).

(...) estou cansada do governo e da IES acharem que estão fazendo um favor pra mim, quando na verdade mal cumprem com a sua obrigação. Muitos simplesmente ignoram a nossa existência aqui e acham um insulto quando dizemos desigualdade social. Insulto (...) é um professor dizer na sala que todos ali presentes eram da classe A. Insulto é ter que comer salgados para economizar ou o custo que temos com xerox, livros e outras coisas, que ninguém liga para como faremos para pagar. (...) [Precisamos] mudar essa agressão mascarada que sofremos! (Grupo Virtual - P12).

No grupo virtual as pesquisadoras perceberam que alguns estudantes ainda afirmam que o programa serviu seu propósito, dando acesso ao Ensino Superior, como apresentado por Costa (2008), porém não abrangendo a permanência do estudante.

De fato, o ProUni não tira ninguém da miséria. É claro que não podemos deixar de lembrar que dar estudo é uma forma de auxiliar as pessoas a saírem da miséria por si só, mas o ProUni não garante - por que não dá meios para tal exceto a bolsa - que o aluno se forme. Sem as políticas de permanência serem melhoradas pelo MEC as taxas de evasão dos alunos prounistas continuará crescente, e o ProUni continuará não sendo o programa "modificador de realidades" que o governo brasileiro prega (Grupo Virtual - P10).

Outros estudantes acreditam que:

Educação é um direito seu, não é uma caridade da faculdade pois como discutido nogrupo elaé isenta de $80 \%$ do imposto ou até $100 \%$ se for filantrópica no caso da IES. Não é também uma caridade do governo, pois isso é uma tentativa de corrigir uma falha por não ter uma vaga em uma universidade pública que também seria GRATUITO. Considero correto o estudarmos de graça e ainda receber um auxílio-moradia, pois é muito alto o número de estudantes que desistem do curso ou acabam arrumando um emprego para se manter na faculdade e com isso prejudicam seu desempenho acadêmico, ainda mais em cursos integrais como os da IES (Grupo Virtual - P43).

A fim de caracterizar a compreensão do processo de inserção a IES pelos bolsistas do ProUni, algumas categorias foram encontradas no grupo virtual e presencial: Solidariedade entre prounistas, Preconceito, Assistência \& Permanência Estudantil e Organização do grupo. Percebeu-se a partir da passagem do grupo virtual, que a falta de iniciativa para o conhecimento sobre o programa pelos estudantes dificultou a organização dos prounistas até um certo momento, retardando as possíveis conquistas do grupo presencial. Como, por exemplo, na escrita do participante 10: "Ai gente! Na boa, falta vocês lerem o manual do bolsista.... Não ligo de vocês perguntarem as coisas, mas é que isso está claro lá..." (Grupo Virtual - P10). Ainda assim, os estudantes eram solidários entre si quando precisavam de alguma informação sobre o programa, ou quando $\mathrm{P} 42$ foi discriminada na universidade por seus colegas e P41 se propôs a ajudá-la a superar aquela dificuldade (DC02).

Entende-se, então, que se os estudantes tivessem um maior conhecimento sobre o Programa, como ele funciona, o real motivo que foi criado, como foi, e é implantado, os deveres e direitos (como a Bolsa Permanência) poderiam ter um avanço nas buscas por permanência. Porém, com o desdobramento da organização a partir das reuniões, as discussões sobre apoio jurídico, a construção do material aos ingressantes e atividades para novos estudantes ingressantes na IES pelo ProUni feita pelo grupo presencial, vistas na passagem podem ser caracterizadas como um grande avanço do grupo presencial, e consequentemente a todos os estudantes, já que esses visam conquistas em relação à assistência estudantil.

No fim, foi proposta uma atividade com advogado e amigo de um estudante prounista para que tirasse as dúvidas jurídicas sobre o ProUni para os estudantes, e nessa atividade estariam na mesa o advogado e a representante atual do Fórum de Prounistas da IES (DC03). 
O material para ingressantes no programa é o que tem de mais claro no avanço dessa organização, pois, visando esclarecer dúvidas, apresenta dados sobre a IES, detalha o que é o ProUni e apresenta dados importantes sobre a Bolsa Permanência, entre outros. O relato a seguir do grupo virtual fez parte de pontos a serem levantados e colocados no manual do estudante prounista, construído pelo movimento.

\section{[Sobre] BOLSA PERMANÊNCIA:}

- gastos com xerox, alimentação, transporte, materiais e etc. são (muito) maiores que o auxílio que o governo disponibiliza (a bolsa é pouca e tudo na IES é caro).

- algumas Universidades disponibilizam ajuda de custo para os prounistas; como a IES ajuda a gente? Colocando um restaurante com almoço a quase 30 reais/kg?? (Grupo Virtual - P34).

Essas passagens podem ser relacionadas à consciência em si de Iasi (2011), pois os estudantes prounistas consideram-se pertencentes ao mesmo coletivo, debatendo as injustiças vividas por eles, pensando conjuntamente em propostas de ação para mudar sua realidade, mesmo que não as coloquem em prática.

A fim de analisar a vivência dos bolsistas e seus sentimentos frente essa vivência podemos identificar, principalmente, a categoria Preconceito retratada também pela impotência sentida pelos prounistas. Esse preconceito está relacionado ao fato dos estudantes serem baixa renda e não terem como se manter dentro da universidade. Ao mesmo tempo, apresentam-se as categorias Assistência \& Permanência Estudantil e Comprovação de renda, como mostram as passagens do diário de campo e grupo virtual, respectivamente.

P41 ficou malvista dentro do curso e era apontada como ladra e charlatã "por ser prounista". Os alunos ainda afirmaram que se ela não tem dinheiro para continuar no curso e comprar os materiais, era melhor sair e largar a faculdade, pois lá é lugar de gente honesta e que tem dinheiro. Alguns professores também disseram à $\mathrm{P} 41$ que para cursar a faculdade é necessário muito dinheiro e investimento, e que se os estudantes bolsistas não tinham condições de pagar tais instrumentos (os que custam, ao todo, cerca de $\mathrm{R} \$ 15 \mathrm{mil}$ ) deve- riam escolher outro curso como Licenciatura, Pedagogia, entre outros. P41 ficou muito abalada, queria ir embora e sair dali, estava entrando em depressão (DC02).

A discriminação e descaso com os bolsistas do ProUni ocorrem diretamente na IES. (...) Só para esclarecer, a discriminação e descaso ocorrem por parte da universidade e não dos alunos (Grupo Virtual, P13).

(...) porém preconceito dos outros sobre os prounistas ocorre e muito, acarretando em alunos oprimidos que por sua vez, acabam por não reivindicarem seus direitos (Grupo Virtual, P42).

Essas dificuldades vivenciadas pelos estudantes, como alimentação cara, falta de livros nas bibliotecas, xérox caros, são fatores muito importantes para que a IES garanta assistência aos prounistas e assim, eles consigam permanecer na IES (Vasconcelos, 2010). Percebemos que relatos se complementaram, ou seja, afirmam que há discriminação e preconceito tanto da IES em relação à infraestrutura, quanto dos outros estudantes e professores. Também percebemos o sofrimento psíquico que vivenciam por sofrerem o preconceito e dificuldades dentro da universidade.

O processo de comprovação de renda anual é legalizado segundo o SisProUni (ProUni, 2005), pois cada universidade tem o direito de complementar o processo de comprovação de acordo com sua avaliação interna. Porém, os estudantes acreditam que é um processo invasivo e que traz sofrimento a eles.

(...) semestralmente os estudantes da IES tem que comprovar que são pobres (...) para garantir que não enriqueceram de um semestre pra outro. Há um desconforto muito grande em todos os estudantes sobre essa questão. Há um medo generalizado em perder a bolsa, se não entregarem os documentos corretos (...) (DC03).

Nossa! Como é difícil conseguir todos os papéis e comparecer no dia marcado... é ilegal... nos últimos anos tenho sofrido muito dentro da IES, e a única coisa que ela sabe fazer é cobrar esses papéis e tchau, tenho que suportar passar o dia sem comida etc. (Grupo Virtual - P51) 
Nesse âmbito, a atuação multidisciplinar da equipe técnica com profissionais de Psicologia e Serviço Social pode auxiliar na orientação aos estudantes, como propõe Bisinoto et al. (2011), gradativamente, para fortalecê-los, a fim de se organizarem para melhorar sua vivência na IES, como também propõe Martín-Baró (1996).

Por último, e não menos importante, em relação ao objetivo geral da pesquisa pode-se considerar que, por criarem o Fórum de Prounistas e se organizarem coletivamente, os estudantes já estão a um passo a frente no processo de tomada de consciência. Esse processo é dinâmico (Iasi, 2011), e se origina na mudança da realidade e não em sua adaptação (Vieira, \& Ximenes, 2008).

A primeira forma de consciência para Iasi (2011) é a alienação. Os estudantes que participaram do grupo virtual, assim como os do Fórum de Prounistas, não defendem a ideologia dominante, fazem uma crítica direta a ela e se organizam de forma a mudar essa sociedade. Duarte (2004), fundando-se em Marx, acredita que a alienação é a dissociação entre o que o indivíduo faz daquilo que motiva aquela ação e pode ser uma alienação da natureza, de si mesmo e de sua espécie. Com isso não podemos dizer que, todas as pessoas do grupo virtual apresentam a primeira forma de consciência, pois não há dissociação entre a ação pela luta por assistência estudantil e o motivo dessa ação. Assim, com isso, não podemos dizer que, no grupo presencial, tem pessoas alienadas, pois não há dissociação entre a ação pela luta por assistência estudantil e o motivo dessa ação.

Já a segunda forma de consciência, segundo Iasi (2011) é a consciência de si o que poderia ser considerado a consciência da reivindicação, ou seja, a superação da alienação. Acontece no reconhecimento do outro como companheiro no embate contra a injustiça em que vivem. É a chave da reivindicação coletiva, é a forma mais básica dos movimentos sociais. A maioria dos estudantes do Fórum de Prounistas tem essa forma de consciência, pois eles se reconhecem como um coletivo com objetivos comuns.

A terceira forma de Consciência, a para si (Iasi, 2011), pode ser considerada a consciência de classe, ou revolucionária, pois, leva o sujeito à práxis, sendo a mais completa e emancipadora. A conscientização é ver a realidade com o olhar mais crítico, tendo a ação como meio e a mudança social como fim (Freire, 1979). Apesar de ser extremamente difícil essa afirmativa, somente uma estudante de Medicina e uma de Psico- logia que apresentam a consciência para si. Elas atuam no Fórum de Prounistas, mas também em outros movimentos sociais, como Centros e Diretórios Acadêmicos dos respectivos cursos, movimentos de área, DCE, coletivos estudantis e movimentos sociais de suas cidades natal. Outra estudante apresentou a consciência para si em algumas situações e discussões no grupo, mas como sabemos que o processo de tomada de consciência é dinâmico, por vezes apresentou a consciência de si, quando defendeu ações paliativas sobre o ProUni e disse que "é melhor o ProUni que nada".

A atuação em diversos movimentos auxilia na atuação dentro do grupo presencial, trazendo discussões de diversos locais em que elas não estão inseridas, resultando inclusive numa possível nacionalização do Fórum e, consequentemente, a luta por assistência estudantil, depois de fortalecê-lo na IES em que estão inseridas. $\mathrm{O}$ fato de alguns estudantes participarem do grupo virtual no Fórum de Prounistas não significa, necessariamente, que manifestam tem esse tipo de consciência, pois, não basta apenas uma ação, e sim uma ação com intenção de mudança, fato que não acontece na maioria dos estudantes dos dois grupos, presencial e virtual.

Os participantes do grupo virtual, ao serem analisados posteriormente, não construíram o grupo presencial, como os próprios prounistas chegaram a comentar, pois nunca viram nenhuma ação conseguir melhorias para a população dos estudantes. Os pensamentos fatalistas dificultam o processo de tomada de consciência, por isso é necessário o debate e aprofundamento das condições objetivas, para mudar essa realidade. Podemos relacionar a consciência semi-intransitiva de Vieira e Ximenes (2008) com o fatalismo descrito por Guzzo (2010) - já que nos dois casos o indivíduo vê a realidade como dada, achando que não pode modificá-la. O processo de tomada de consciência promove (Duarte, 2004; Vieira, \& Ximenes, 2008) a participação popular, ação coletiva, para a libertação e emancipação como única saída. O psicólogo pode atuar de forma a auxiliar no processo de tomada de consciência dos estudantes no Fórum de Prounistas, a partir de uma ação conjunta na comunidade acadêmica, sendo mediador contra as opressões vivenciadas por esses estudantes. A atuação do psicólogo na IES pode, também, auxiliar nas discussões sobre os direitos dos estudantes, ou seja, visando uma ação conjunta de estudantes por educação gratuita, pública, de qualidade para eles (Guzzo, 2007). 


\section{Conclusões e Considerações finais}

Considerando o objetivo principal desse trabalho foi possível identificar diferenças no processo de tomada de consciência dos estudantes prounistas frente à conjuntura em que vivem e relacionando-a com os resultados obtidos das diferentes técnicas utilizadas - diário de campo e etnografia virtual. Ficaram menos evidentes as formas do processo de tomada de consciência no grupo virtual, tanto é que apenas a primeira forma de consciência - alienação - foi encontrada na maioria dos estudantes. Ao contrário do Fórum de Prounistas presencial é possível identificar todas as formas de consciência descritas por Iasi (2011), por estarem vivenciando a organização conjunta, mesmo que com dificuldades e falhas.

Ainda assim, as dificuldades encontradas nesse processo, como a falta de organização do Fórum e a pouca participação no grupo virtual, fizeram com que nem todos os elementos desse processo pudessem ser analisados, somado ao fato do processo de tomada de consciência ser dinâmico e, com isso, tornar mais difícil a caracterização dos participantes, sendo uma limitação desse estudo. Sendo a proposta do MHD explicitar os elementos que contribuem para a mudança do processo de consciência, entende-se que essa pesquisa atingiu seus objetivos e conseguiu trazer à tona os principais elementos para esse processo de mudança.

A partir da análise dos dados apresentada anteriormente conclui-se que o ProUni, apesar de mudar, significativamente, o acesso de jovens no ensino superior, não é a melhor forma de assegurar direito à educação superior aos estudantes baixa renda, pois não garante a permanência do estudante na IES, faltando alimentação a baixo custo, restaurante universitário, auxílio financeiro, como bolsas trabalho, entre outras formas de assistência estudantil, já descritas na introdução teórica. Além disso, pelas postagens do grupo virtual e dos temas discutidos no Fórum de Prounistas e descritos nos diários de campo, os estudantes têm consciência que têm direito à educação pública, gratuita, de qualidade, e defendem esse direito dentro dos espaços em que vivem, porém, muitas variáveis são avaliadas no processo de escolha entre ProUni e IES pública, como distância da família e gastos com viagem.

Frente a todas as dificuldades relatadas pelos estudantes, entende-se que a assistência estudantil é necessária para a permanência no Ensino Superior, tanto nas IES privadas quanto públicas, também a fim de concluir uma graduação com qualidade, não só em relação ao Ensino. Essa assistência deve vir como iniciativa da IES e não do governo, já que os estudantes participantes do grupo virtual e do Fórum de Prounistas são contra mais investimento público em IES privadas, como discutido no grupo virtual.

O trabalho do psicólogo no Ensino Superior tem se mostrado essencial, a fim de orientar o estudante prounista, visando seu fortalecimento para que ele possa, então, mudar sua realidade. Além disso, a organização dos estudantes, com apoio do psicólogo no Ensino Superior, como proposto por Bisinoto e Marinho-Araújo (2011), já que as principais ações do psicólogo estão relacionadas às dificuldades que os estudantes vivenciam cotidianamente, também se faz necessária, pensando conseguir melhorias para a permanência do estudante. A atuação do psicólogo na IES pode, inclusive, auxiliar nas discussões sobre os direitos dos estudantes, ou seja, visando uma ação conjunta de estudantes por educação gratuita, pública, de qualidade para os mesmos (Guzzo, 2007).

Em relação às categorias de preconceito e solidariedade entre prounistas, assim como o fato de terem mais mulheres no movimento que homens, são necessários mais estudos na área para discutir essas vivências e questões.

\section{Referências}

Almeida, M. A. (2009). Universidade para todos: o PROUNI na visão dos bolsistas de uma instituição de ensino superior (Dissertação de mestrado). Pontifícia Universidade Católica de Campinas, Campinas, SP.

Almeida, S. C. (2006). O avanço da privatização na educação brasileira: o ProUni como uma nova estratégia para a transferência de recursos públicos para o setor privado (Dissertação de mestrado). Universidade Federal Fluminense, Niterói, RJ.

Amaral, A. (2009). Autonetnografia e inserção online: o papel do pesquisador insider nas subculturas da web. Revista Fronteiras: Estudos Midiáticos, 11(1): 14-24. https://doi.org/10.4013/fem.2009.111.02 
Bisinoto, C., \& Marinho-Araújo, C. M. (2011). Psicologia escolar na educação superior: atuação no Distrito Federal. Psicologia em Estudo, 16(1), 111-122. https://doi.org/10.1590/S1413-73722011000100013

Bisinoto, C., Marinho, C., \& Almeida, L. (2011). A atuação da Psicologia Escolar na Educação Superior: algumas reflexões. Revista Portuguesa de Pedagogia, 45(1), 39-55.

Carvalho, C. H. A. (2006). O PROUNI no governo Lula e o jogo político em torno do acesso ao ensino superior. Educação e Sociedade, 27(96): 979-1000. https://doi.org/10.1590/S0101-73302006000300016

Carvalho,T. O., \&Marinho-Araújo, C. M. (2009).Psicologia escolar no Brasil eno Maranhão: percursos históricos e tendências atuais. Psicologia Escolar Educacional, 13(1), 65-73. https:// doi.org/10.1590/S1413-85572009000100008

Costa, F. S. (2008). Políticas públicas de educação superior: Programa Universidade para Todos: um olhar dos alunos beneficiários na PUC-SP (Dissertação de mestrado). Pontifícia Universidade Católica de São Paulo, São Paulo, SP.

Duarte, N. (2004). Formação do indivíduo, consciência e alienação: o ser humano na psicologia de A. N. Leontiev. Caderno Cedes, 24(62), 44-63. https://doi.org/10.1590/S0101-32622004000100004

Foreque, F. (2013, 4 de agosto). ProUni rende isenção fiscal de $\mathrm{R} \$ 4$ bi a faculdades. Folha de São Paulo. Recuperado de http://wwwl.folha.uol.com.br/cotidiano/2013/08/1321455-ProUni-rende-isencao-fiscal-de-r-4-bi-a-faculdades-privadas.shtml

Freire, P. (1979). Conscientização: teoria e prática da libertação: uma introdução ao pensamento de Paulo Freire. São Paulo, SP: Cortez e Moraes.

Freire, P. (1984). Educação como prática da liberdade. Rio de Janeiro, RJ: Paz e Terra.

Guzzo, R. S. L. (2010). Educação para a liberdade, psicologia da libertação e a psicologia escolar: uma práxis pra a liberdade. In S. F. C. Almeida (Org), Psicologia escolar:ética e competência na formação e atuação profissional (pp. 169-178). Campinas, SP: Alínea.

Guzzo, R. S. L. (2007). Psicologia e educação: que compromisso? Que relação? In A. V. B. Bastos, \& N. M. D. Rocha (Orgs.), Psicologia: novas direçães no diálogo com outros campos do saber (pp. 357-378). São Paulo: Casa do Psicólogo.

Hine, C. (2000). Virtual ethnography. London, Sage.

Iasi, M. L. (2011). Ensaios sobre consciência e emancipação. São Paulo: Expressão Popular.

Jeffrey, B., Bradshaw, P., Twining, P., \& Walsh, C. (2010). Ethnography, education and on-line research. In European Conference of Educational Research (1-17). Univesity of Helsinki, Finland. Recuperado de http://oro.open.ac.uk/22868/2/Jeffrey_et_al.pdf

Jorge, J. (2009). Relatório de auditoria operacional: Programa Universidade para Todos (ProUni) e Fundo de Financiamento ao Estudante do Ensino Superior (FIES). Brasília, DF: Tribunal de Contas da União. Recuperado de http://portal.tcu.gov.br/lumis/portal/file/fileDownload.jsp?inline=1\&fileId=8A8182A14D92792C014D9283C47B77D7

Lacerda Junior, F., \& Guzzo, R. S. L. (2011). Sobre o sentido e a necessidade do resgaste crítico da Obra de Martín-Baró. In R. S. L. Guzzo, \& F. Lacerda Junior (Orgs), Psicologia social para América Latina: o resgaste da psicologia da libertação (pp. 15-37). Campinas, SP: Alínea.

Leher, R. (2004). Para silenciar os campi. Educação \& Sociedade, 25(88), 867-891. https:// doi.org/10.1590/S0101-73302004000300011

Lima, K. (2007). Contra-reforma na educação superior: de FHC a Lula. São Paulo, SP: Xamã.

Martín-Baró, I. (1985). La Encuesta de opinión publica como instrumento desideologizador. Cuadernos de Psicología, 9(35): 9-22. Recuperado de http://www.uca.edu.sv/coleccion-digital-IMB/articulo/la-encuesta-de-opinion-publica-como-instrumento-desideologizador/

Martín-Baró, I. (1996). O papel do psicólogo. Estudos de Psicologia, 2(1), 7-27. https:// doi.org/10.1590/S1413-294X1997000100002

Marvakis, A. (2011). La psicologia (crítica) permanentemente em la encrucijada: sirvientes del poder y herramientas para la emancipación. Teoría y Crítica de la Psicologia, 1, 122-130. Recuperado de http://www.teocripsi.com/ ojs/index.php/TCP/article/view/40/62 
Mercado, L. P. M. (2012). Coleta de dados na pesquisa qualitativa online utilizando a etnografia virtual. Memorias Virtual Educa, Mexico, DF, Mexico. Recuperado de http://www.virtualeduca.info/fveduca/pt/guia-del-participante-2011/148-coleta-de-dados-na-pesquisa-qualitativa-online-utilizando-a-etnografia-virtual

Montardo, S., \& Passerino, L. (2006). Estudo dos blogs a partir da netnografia: possibilidades e limitações. Revista Novas Tecnologias na Educação ,4(2): 1-10. Recuperado de http://seer.ufrgs.br/index.php/renote/article/view/14173/8102

Montero, M. (2006). Dos tecnicas auxiliares en la investigacion e intervencion comunitarias: las anotaciones o diario de campo y eI uso de documentos secundários. In M. Montero (2006), Hacer para transformar: el método de La psicologia comunitária. Buenos Aires: Paidos.

Parker, I. (2009). Psicologia crítica: ¿Qué es y qué no es?. Revista Venezolana de Psicología Clínica Comunitaria. 8, 139-159. Recuperado de http://www.psi.uba.ar/academica/carrerasdegrado/psicologia/sitios_catedras/electivas/067_psico_preventiva/material/bibliografia/psicologia_critica.pdf

Parker, I. (2005). Qualitative psychology: introducing radical research. London: Open University Press.

Paulo Netto, J. (2011). Introdução ao estudo do método em Marx. São Paulo, SP: Expressão Popular.

Pereira Filho, E. S. (2011). Perfil dos jovens universitários bolsistas do ProUni: em estudo de caso na UNISINOS (Tese de doutorado). Universidade do Vale do Rio dos Sinos, São Leopoldo, RS.

Pieniz, M. (2009). Novas configurações metodológicas e espaciais: etnografia do concreto à etnografia do virtual. Revista Elementa. Comunicação e Cultura, 1(2).

PROUNI - Programa Universidade para Todos. (2005). Bolsa permanência. Brasília, DF: Ministério da Educação. Recuperado de http://ProUniportal.mec.gov.br/bolsa-permanencia

PROUNI - Programa Universidade para Todos. (2013). Dados e estatísticas. Recuperado de http://ProUniportal. mec.gov.br/dados-e-estatisticas/

PROUNI - Programa Universidade para Todos. (2008). O programa. Brasília, DF: Ministério da Educação. Recuperado de http://ProUniportal.mec.gov.br/o-programa

Rocha, M. A. M. (2011). Processo de inclusão ilusória: o jovem bolsista universitário. Jundiaí, SP: Paco Editorial.

Serpa, M. N. F. \& Santos, A. A. A. (2001). Atuação no ensino superior: um novo campo para o psicólogo escolar. Psicologia Escolar e Educacional, 5(1), 27-35. https:// doi.org/10.1590/S1413-85572001000100004

Silva, M. C. M., Koike, M., Manezenco, R., \& Lacks, S. (2004). A contra reforma da educação superior. Brasília, DF: Grupo de Trabalho de Política Educação.

Vasconcelos, N. B. (2010). Programa Nacional de Assistência Estudantil: uma análise da evolução da assistência estudantil ao longo da história da educação superior no Brasil. Ensino em Re-vista, 2(3), 399-411. Recuperado de http://www.seer.ufu.br/index.php/emrevista/article/view/11361/6598

Vieira, E. M., \& Ximenes, V. M. (2008). Conscientização: em que interessa este conceito à psicologia. Psicologia Argumentos, 26(52), 23-33.

Weber, D. (2011, 20 de agosto) ProUni: um em cada quatro alunos abandona o programa; a maioria abre mão da bolsa, mas continua estudos, diz MEC. O Globo. Recuperado de http://oglobo.globo.com/politica/ProUni-um-em-cada-quatro-alunos-abandona-programa-maioria-abre-mao-da-bolsa-mas-continua-estudos-diz-mec-2868441

\section{Flávia de Mendonça Ribeiro}

Doutoranda em Psicologia na Pontifícia Universidade Católica de Campinas, Campinas, SP, Brasil.

E-mail: ribeiro.m.flavia@gmail.com

\section{Raquel Souza Lobo Guzzo}

Professora Doutora da Pós-graduação em Psicologia pela Pontifícia Universidade Católica de Campinas, Campinas, SP, Brasil.

E-mail: rslguzzo@gmail.com 
Endereço para envio de correspondência:

PUC- Campinas - Campus II - Av. John Boyd Dunlop - s/nº. Jd. Ipaussurama. CEP: 13060-904

Campinas - SP, Brasil.

Agência Financiadora: CNPq - Conselho Nacional de Desenvolvimento Científico e Tecnológico

(Número do processo - 130368/2012-1)

Recebido 26/04/2016

Reformulação 13/12/2016

Aprovado 25/04/2017

Received $04 / 262016$

Reformulated $12 / 132016$

Approved 04/25/2017

Recebido 26/04/2016

Reformulado 13/12/2016

Aceptado 25/04/2017

Como citar: Ribeiro, F. M., \& Guzzo, R. S. L. (2017). Consciência de estudantes prounistas sobre sua inserção no ensino superior. Psicologia: Ciência e Profissão, 37(2), 418-431. https://doi.org/10.1590/1982-3703001472016

How to cite: Ribeiro, F. M., \& Guzzo, R. S. L. (2017). Awareness of ProUni students about their insertion in higher education. Psicologia: Ciência e Profissão, 37(2), 418-431. https://doi.org/10.1590/1982-3703001472016

Cómo citar: Ribeiro, F. M., \& Guzzo, R. S. L. (2017). La concientización de los estudiantes prounistas en su inserción en la educación superior. Psicologia: Ciência e Profissão, 37(2), 418-431. https://doi.org/10.1590/1982-3703001472016 